\title{
Functional Outcome of Fracturedistal End Radius Treated with Volar Locking Plates: A Prospective Study
}

\author{
Savith Shetty ${ }^{1}$, Nithin Chandra Babu ${ }^{2}$ \\ ${ }^{1}$ Assistant Professor, D.Ortho., DNB, Department of Orthopaedics, Yenepoya University, Deralakatte, Karnataka, India \\ ${ }^{2}$ Post Graduate Student, Department of Orthopaedics, Yenepoya University, Deralakatte, Karnataka
}

\begin{abstract}
Background: Diverse options are available for treatment of closed distal radius fractures .However most of these treatment modalities are unable to provide early functional rehabilitation. Locking compression plates provides angular and axial stability and facilitates early functional rehabilitation.Advantages of volar approach to distal radius including avoidance of devascularization of distal fragments and damage to extensor tendons associated with dorsal approach. Methods: From March 2016 to May 2017, twenty patients with distal radius fractures were treated with open reduction and internal fixation using volar locking compression plates at our institute.All patients had radiographic and clinical follow-up performed atone, three,six months and one year. Results: At final evaluation all patients showed good range of motion of wrist-average dorsiflexion $62.7^{0}$,palmar flexion $54.8^{0}$,radial inclination $15^{0}$, ulnar inclination $25.5^{\circ}$,pronation $69^{\circ}$, supination $68.3^{\circ}$. Radiologically, average volar tilt in our study was $6^{0}$, average radial inclination was $21.2^{0}$, average radial length $3.6 \mathrm{~mm}$ and articular congruity $0.5 \mathrm{~mm}$. Conclusions: It is a safe and effective method with minimum tissue damage,good primary stability of fracture and facilitates early active motion from first post-operative day without compromising fracture reduction.
\end{abstract}

Keywords: Volar locking plates, Distal radius fractures, colles fracture

\section{Introduction}

Distal radius fractures are referred to as Colles, Barton or Smith fractures depending on the involvement of radiocarpal joint surfaces and direction of displacement of fracture fragments[1].

As distal radius is important in kinematics of radio-carpal and radio-ulnar joints, for good clinical outcome, open reduction of articular surface and restoration of radial length, volar angulation and radial inclination are prerequisites. Reconstruction of the articular congruity and stable fixation reduces incidence of post-traumatic osteoarthritis and allows early range of movement.

Distal radius fractures are more common in elderly individuals.

Recently the development of locking-plate technology has changed the way in which many fractures are managed. Locking compression plates utilize threaded screw heads that lock into plate holes when screws are tightened providing angular and axial stability and minimizing possibility of screw loosening there by facilitating early functional rehabilitation. Volar approach has several advantages including, more special volar aspect of the distal radius and avoidance of dorsal dissection with associated devascularization of distal fragments and damage to extensor tendons, thereby facilitating early functional use of hand while minimizing need for bone grafting.

The purpose of this study is to present our experience in treating twenty displaced distal radius fractures with volar locking plate and immediate functional rehabilitation from first day post-op.

\section{Review of Literature}

In 1783 Pouteau was first to describe the fracture of lower end radius[2].

In 1814 Abraham Colles described fracture of lower end radius and published it in the Edinburgh Medical and Surgical Journal.[2].

In 1989, Lafontaine, Hardy and Delince identified five predictors of instability in a study conducted by them: a patient over sixty years, an intra-articular fracture, dorsal comminution, dorsal angulation of more than $20^{\circ}$ and an associated ulnar fracture [3].

In $2005 \mathrm{KK}$ Wong, KW Chavan reported thirty patients of dorsally displaced distal radius fractures fixed by volar locking compression plating. Functional assessment by Gartland and Werley showed 80\% excellent and $16 \%$ good and $4 \%$ poor results[4].

In 2006 Orbay JL,Touhami A., mentioned in article published in Clinical Orthopaedics 2006 that there are several theoretical advantages to approaching and fixing the radius through a volar approach; more space is available, the flexor tendons are further from the bone and pronator quadratus is interposed[5].

In 2008, a study done at orthopaedic department of Mid Staffordshire NHS foundation trust which included thirtynine patients with distal end radius fracture treated with volar locking plate showed mean volar tilt of 9 degrees and according to Gartland and Werley system all patients achieved excellent to good results[6]. 


\section{International Journal of Science and Research (IJSR) \\ ISSN (Online): 2319-7064}

Index Copernicus Value (2016): 79.57 | Impact Factor (2015): 6.391

\section{Objectives}

1) To study twenty patients with fracture distal end radius fracture treated at our hospital with volar locking plates.

2) To access the functional outcome in these patients by checking range of motion and radio graphical evaluation. Thereby coming to conclusion if this mode of treatment is effective in getting good functional outcome in patients with these fractures.

\section{Anatomy}

Normal radiographic relationships [7]

- Radial inclination: averages 23 degrees (range- 13 to 30 degrees)

- Radial length: averages $11 \mathrm{~mm}$ (range - 8 to $18 \mathrm{~mm}$ ).

- Palmar (volar) tilt: averages 11 to 12 degrees (range- 0 to 28 degrees).

\section{Materials and Methods}

From March 2016 to May 2017, 20 patients with distal radius fractures were treated with open reduction and internal fixation using volar locking compression plates at our institute.

Preoperative radiographic evaluation showed an average deformity of $16.8 \mathrm{degrees}$ of dorsal/volarangulation , average radial inclination of 14.25 degrees, average radial shortening of $2.5 \mathrm{~mm}$.

All procedures were performed under general anesthesia.

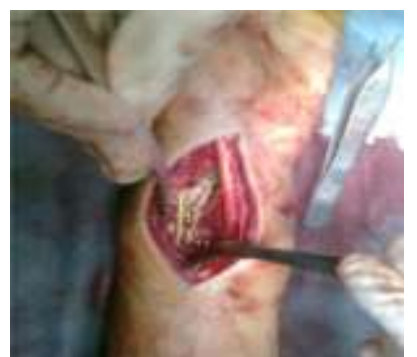

Figure 1: Intra-operative image showing placement of volarlocking plate

Open reduction was performed with the aid of manual traction and manipulation of the fragment and confirmed under the image intensifier. The plates used were $3.5 \mathrm{~mm} \mathrm{~T}$ shaped AO titanium locking compression plates depending on fracture configuration.
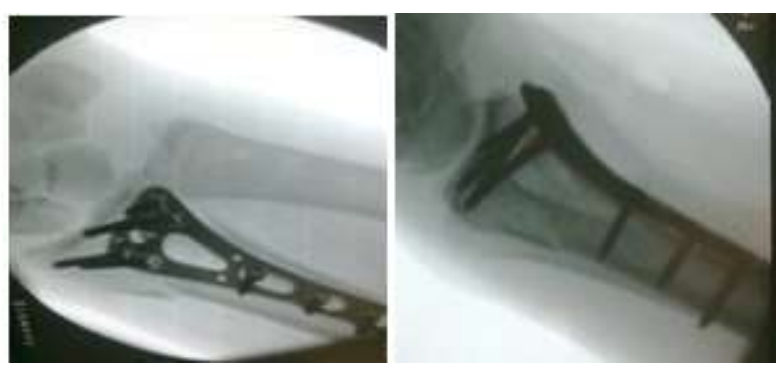

Figure 2: Intra-operative fluoroscopy image showing adequate reduction and fixation.
Post-op management -

- Immediately after surgery below elbow slab was applied on day 0

- From day1, slab removed, dressing done and active finger, wrist motion and forearm rotation were encouraged.

- Post-operative patients were followed up weekly for four weeks and then once in a month for the next three months and thereafter at 6 months and lastly one year.

- Final radiological results were reviewed at final evaluation. Volar tilt, radial inclination, radial length and articular congruency were measured and compared with pre-op data.

\section{Results}

Preop Radiograph:

\begin{tabular}{|c|c|c|c|c|}
\hline $\begin{array}{c}\text { Sl. } \\
\text { No. }\end{array}$ & $\begin{array}{c}\text { D/V } \\
\text { angulation } \\
\text { (degrees) }\end{array}$ & $\begin{array}{c}\text { Radial } \\
\text { inclination } \\
\text { (degrees) }\end{array}$ & $\begin{array}{c}\text { Radial } \\
\text { angulation } \\
\text { (degrees })\end{array}$ & $\begin{array}{c}\text { Loss of Articular } \\
\text { congruity } \\
(\text { mm })\end{array}$ \\
\hline 1 & D-10 & 10 & 0 & 2 \\
\hline 2 & D13 & 11 & 1 & 3 \\
\hline 3 & D-15 & 13 & 3 & 3 \\
\hline 4 & D-10 & 23 & 5 & 1 \\
\hline 5 & v-15 & 12 & 1 & 3 \\
\hline 6 & v-19 & 14 & 3 & 3 \\
\hline 7 & v-13 & 11 & 2 & 2 \\
\hline 8 & D-16 & 16 & 4 & 2 \\
\hline 9 & V-12 & 17 & 1 & 3 \\
\hline 10 & D-21 & 13 & 2 & 1 \\
\hline 11 & D-23 & 11 & 3 & 1 \\
\hline 12 & V-19 & 16 & 0 & 3 \\
\hline 13 & V-16 & 17 & 3 & 3 \\
\hline 14 & D-23 & 21 & 3 & 2 \\
\hline 15 & V-19 & 11 & 5 & 2 \\
\hline 16 & V-16 & 16 & 3 & 1 \\
\hline 17 & D-23 & 12 & 2 & 3 \\
\hline 18 & D-19 & 17 & 1 & 1 \\
\hline 19 & V-13 & 13 & 3 & 2 \\
\hline 20 & V-21 & 11 & 5 & 2 \\
\hline Average & 16.8 & 14.25 & 2.5 & 2.15 \\
\hline & & & & \\
\hline
\end{tabular}

In our study pre-op radiograph evaluation showed average dorsal/volar angulation of 16.8 degrees(ranging from 1023degrees), average radial inclination of 14.25 degrees(ranging from 10-23degrees), average radial shortening of $2.5 \mathrm{~mm}$ (ranging from $0-5 \mathrm{~mm}$ )and average loss of congruity of $2.15 \mathrm{~mm}$ (ranging from $1-3 \mathrm{~mm}$ ).

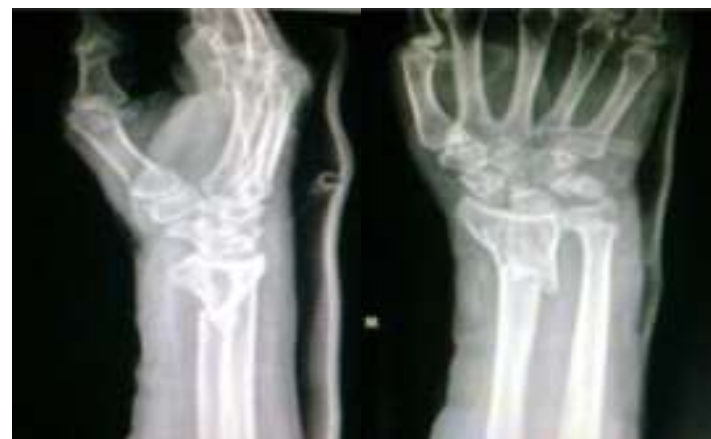

Figure 3: Pre-operative anteroposterior and lateral Xrays

Volume 6 Issue 12, December 2017 www.ijsr.net 


\section{International Journal of Science and Research (IJSR) \\ ISSN (Online): 2319-7064}

Index Copernicus Value (2016): 79.57 | Impact Factor (2015): 6.391

Post-op radiograph:

\begin{tabular}{|c|c|c|c|c|}
\hline Sl.No. & $\begin{array}{c}\text { Volar Tilt } \\
(\text { degrees })\end{array}$ & $\begin{array}{c}\text { Radial inclination } \\
(\text { degrees })\end{array}$ & $\begin{array}{c}\text { Radial } \\
\text { height } \\
(\mathrm{mm})\end{array}$ & $\begin{array}{c}\text { Articular } \\
\text { congruity } \\
(\mathrm{mm})\end{array}$ \\
\hline 1. & 6 & 22 & 4 & 0 \\
\hline 2. & 8 & 24 & 3 & 0 \\
\hline 3. & 8 & 22 & 0 & 0 \\
\hline 4. & 10 & 18 & 2 & 1 \\
\hline 5. & 6 & 20 & 4 & 0 \\
\hline 6. & 10 & 26 & 6 & 1 \\
\hline 7. & 6 & 20 & 3 & 1 \\
\hline 8. & 6 & 22 & 6 & 1 \\
\hline 9. & 8 & 20 & 5 & 1 \\
\hline 10. & 8 & 18 & 3 & 0 \\
\hline 11. & 11 & 22 & 3 & 0 \\
\hline 12. & 6 & 26 & 3 & 0 \\
\hline 13. & 8 & 20 & 4 & 1 \\
\hline 14. & 8 & 22 & 5 & 0 \\
\hline 15. & 8 & 22 & 3 & 1 \\
\hline 16. & 6 & 23 & 0 & 0 \\
\hline 17. & 10 & 18 & 0 & 1 \\
\hline 18. & 10 & 20 & 3 & 1 \\
\hline 19. & 6 & 20 & 3 & 0 \\
\hline 20. & 11 & 22 & 4 & 1 \\
\hline Average & 8 & 21.35 & 3.2 & 0.5 \\
\hline & & & & \\
\hline
\end{tabular}

Volar tilt, radial inclination ,radial length and articular congruity were the various parameters which were used to access the radiographic correction of fracture.

- The average volar tilt in our study was 8degrees (ranging from 6-10 degrees)

- The average radial inclination was 21.5 degrees (ranging from 18-26 degrees)

- The average radial length $3.2 \mathrm{~mm}$ (ranging from 0-6mm) and articular congruity $0.5 \mathrm{~mm}$ (ranging from $0-1 \mathrm{~mm}$ ).

It was also observed that there was not much loss of reduction in all cases on final $\mathrm{X}$-ray evaluation as compared with first post-operativeX-ray.

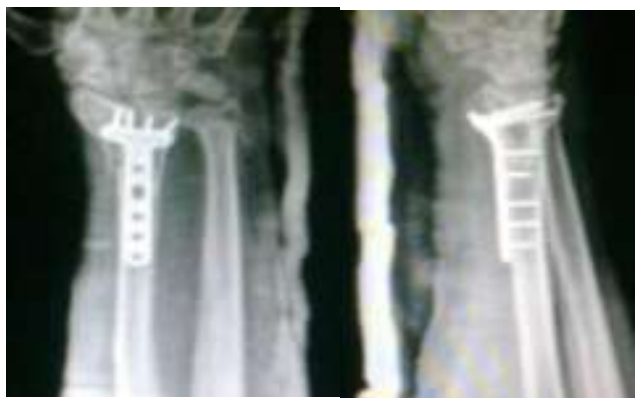

Figure 4: Immediate post-operative Xray.

Range of motion-

\begin{tabular}{|c|c|c|c|c|c|c|}
\hline $\begin{array}{c}\text { Sl. } \\
\text { No. }\end{array}$ & $\begin{array}{c}\text { Dorsi- } \\
\text { flexion } \\
\text { (degrees) }\end{array}$ & $\begin{array}{c}\text { Palmar } \\
\text { flexion } \\
\text { (degrees) }\end{array}$ & $\begin{array}{c}\text { Radial } \\
\text { inclination } \\
\text { (degrees) }\end{array}$ & $\begin{array}{c}\text { Ulnar } \\
\text { inclination } \\
\text { (degrees) }\end{array}$ & $\begin{array}{c}\text { Pronation } \\
\text { (degrees) }\end{array}$ & $\begin{array}{c}\text { Supination } \\
\text { (degrees) }\end{array}$ \\
\hline 1. & 62 & 54 & 12 & 30 & 76 & 71 \\
\hline 2. & 73 & 64 & 13 & 24 & 72 & 69 \\
\hline 3. & 62 & 52 & 15 & 23 & 74 & 66 \\
\hline 4. & 50 & 55 & 18 & 30 & 63 & 59 \\
\hline 5. & 68 & 59 & 17 & 19 & 62 & 62 \\
\hline 6. & 70 & 57 & 20 & 30 & 67 & 68 \\
\hline 7. & 69 & 65 & 12 & 27 & 69 & 73 \\
\hline 8. & 62 & 53 & 16 & 28 & 72 & 76 \\
\hline 9. & 61 & 45 & 15 & 24 & 73 & 71 \\
\hline
\end{tabular}

\begin{tabular}{|c|c|c|c|c|c|c|}
\hline 10. & 50 & 44 & 12 & 20 & 62 & 68 \\
\hline 11. & 70 & 53 & 20 & 20 & 64 & 61 \\
\hline 12. & 62 & 63 & 16 & 19 & 69 & 67 \\
\hline 13. & 58 & 55 & 15 & 27 & 73 & 76 \\
\hline 14. & 60 & 60 & 14 & 26 & 75 & 72 \\
\hline 15. & 70 & 64 & 20 & 22 & 73 & 62 \\
\hline 16. & 52 & 52 & 12 & 27 & 67 & 66 \\
\hline 17. & 54 & 56 & 13 & 28 & 68 & 71 \\
\hline 18. & 70 & 54 & 12 & 21 & 72 & 73 \\
\hline 19. & 64 & 44 & 16 & 24 & 68 & 64 \\
\hline 20. & 68 & 60 & 20 & 27 & 67 & 69 \\
\hline Avg & 62.75 & 55.45 & 15.4 & 24.8 & 69.3 & 68.2 \\
\hline
\end{tabular}

At final evaluation all patients showed good range of motion of wrist-

- Average dorsiflexion 62.75 degrees (ranging from 50-73 degrees)

- Palmar flexion 55.45 degrees (ranging from 52 -65 degrees)

- Radial inclination 15.4degrees (ranging from 12 -20 degrees)

- Ulnar inclination 24.8 degrees (ranging from 19 -30 degrees)

- Pronation 69.3degrees (ranging from 62-76 degrees)

- Supination 68.2 degrees (ranging from 59-76 degrees).

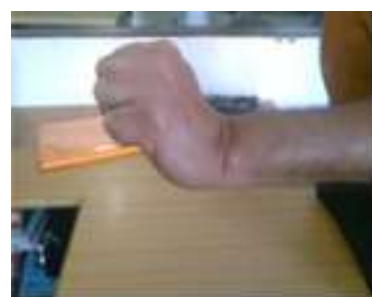

a

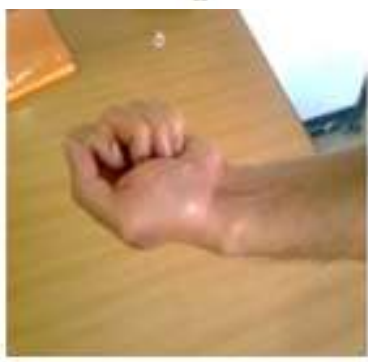

c

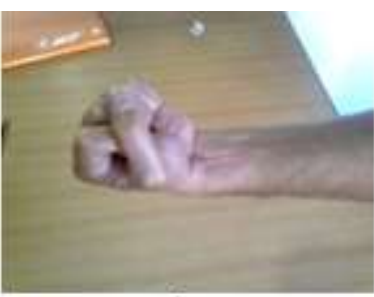

b

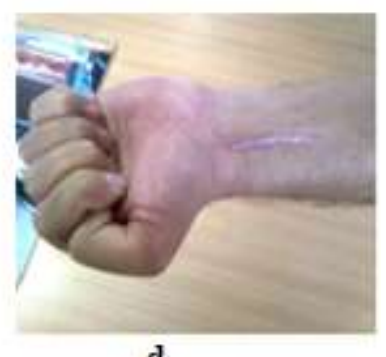

d
Figure 5: Clinical images showing range of motion at final follow-up.

a) Dorsiflexion

b) Palmarflexion

c) Ulnar inclination

d) Radial inclination

\section{Discussion}

Distal radius fractures accounts for up to 10 to $20 \%$ fractures of skeletal system.

Diverse options available in managing these fractures including closed reduction with plaster cast immobilization, pins and plaster, open reduction and internal fixation[8] ,external fixation devices[9]. However none of these treatment modalities are unable to provide early functional rehabilitation. 


\section{International Journal of Science and Research (IJSR) \\ ISSN (Online): 2319-7064}

Index Copernicus Value (2016): 79.57 | Impact Factor (2015): 6.391

The benefits of this method of volar locking compression plating includes early return of function, improved final motion, virtual elimination of extensor tendon problems[10].

Dorsal approach requires dissection of extensor retinaculum. The extensor pollicislongus tendon commonly exposed to mechanical attrition by plate and screws. In volar approach space on the volar aspect of distal radius provides more room for implant placement and pronator quadratus act as barrier to minimize irritation to flexor tendons.

\section{Conclusion}

1) We found that volar locking compression plating is successful in stabilizing distal radius fractures giving excellent to good results.

2) It is a safe and effective method of treating distal radius fractures facilitating early active motion from first postoperative day without compromising fracture reduction.

3) We have clearly shown that active mobilization can be started from the day one post-op achieving early return of function and improved final functional range of motion.

\section{References}

[1] Dobyns,J.H. and Lincheild; fractures dislocations of wrist. In Fractures in Adults, edited by C.A.RockwoodJr and D.P. Green ed2, vo1, pp. 411-509,J.B.Lippincot, 1984.

[2] Colles A: Historical paper on the fracture of the carpal extremity of the radius [1814] Injury 1970; 2: 48-50.

[3] Lafontaine M, Hardy D, Delince P.Stability assessment of distal radius fractures. Injury 1989;20:208-10.

[4] Kk Wong, KW chan, volar fixation of dorsally displaced distal radius fracture using lockingcompression plate. Journal of orthopaedic surgery 2005:13(2) 153-157.

[5] Orbay JL, Touhami A.Current concepts in volar fixedangle of unstable distal radius fractures. ClinOrthop 2006;445:58-67.

[6] N.D.Downing,A.Karantana,A revolutioninmanagement of the fractures of distal radius.J Bone Joint Surg [Br] 2008;90-B:1271-5.

[7] Hand book of fractures $3^{\text {rd }}$ edition , Keneth J. Koval, Joseph D. Zuckerman.

[8] Beharrie, Andrew. MD :Functional outcomes after open reduction and internal fixation for treatment of distal radius fractures in patient above 60 years of age :J.Orthopaedic Trauma.18(10):680-686.

[9] Teng-Le Huang, ChingKuei Huang, Jung-Kuang; Operative treatment of intraarticular distal radius fractures using the small AO external fixation device. : J. Chin Med Association.Oct 2005, Vol 68.no 10475.

[10] Jorge L.Orbay, MD: and AmelTouhami, MD : Current concepts in volar fixed -angle fixation of unstable distal radius fracture: Clinicalorthopaedics And Related Research:2006 445 ,pp. 58-67. 